\title{
Erratum to: Health, disability and quality of life among trans people in Sweden-a web- based survey
}

Galit Zeluf $^{1 *}$, Cecilia Dhejne ${ }^{2,3}$, Carolina Orre ${ }^{4}$, Louise Nilunger Mannheimer ${ }^{5,6}$, Charlotte Deogan ${ }^{1,6}$, Jonas Höijer ${ }^{7}$ and Anna Ekéus Thorson ${ }^{1}$

\section{Erratum}

In the publication of this article [1] it was brought to our attention that the last sentence on page 12 incorrectly states: "Legal gender recognition, in the context of this study, is a precondition for access to genderconfirming health care". The correct sentence should read: "Gender-confirming health care, in the context of this study, is a precondition for access to legal gender recognition".

This sentence has been updated in the original article.

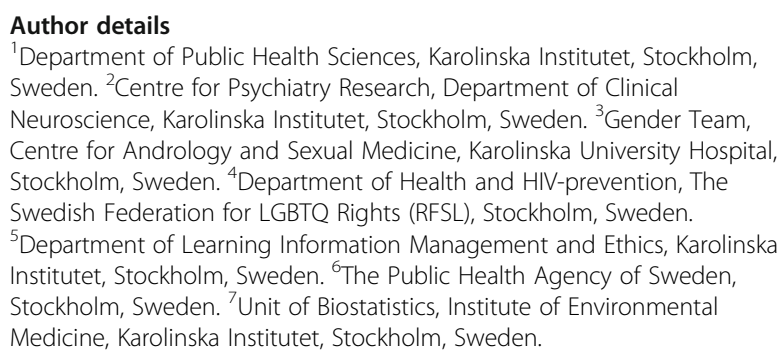

Published online: 14 October 2016

\section{Reference}

1. Zeluf $\mathrm{G}$, et al. Health, disability and quality of life among trans people in Sweden-a web-based survey. BMC Public Health. 2016;16:903. doi:10.1186/ s12889-016-3560-5.

\footnotetext{
* Correspondence: galit.zeluf.1@ki.se

${ }^{1}$ Department of Public Health Sciences, Karolinska Institutet, Stockholm,

Sweden

Full list of author information is available at the end of the article
} 